\title{
ANALYSIS OF MOBILE PAYMENT INFLUENCING FACTORS
}

\author{
Sitalakshmi Venkatraman \\ School of Engineering, Construction and Design (IT), \\ Melbourne Polytechnic, Australia
}

\begin{abstract}
With the exponential proliferation of mobile devices in the consumer market, wireless e-business is emerging as a key area to revolutionise industries. In the past few years, industry has witnessed an increase in the adoption of mobile payment and billing methods that leverage on wireless technologies. Yet, the success of mobile payments in businesses much depends on many factors such as, type of wireless technologies used, security options available, the players involved and their influencing m-business models. This paper examines mobile payments in both technical as well as business perspectives. It identifies and analyses the influencing factors from multi-dimensions that would be useful for adopting mobile payments.
\end{abstract}

\section{KEYWORDS}

Mobile payments, Wireless technologies, Business models. M-commerce

\section{INTRODUCTION}

Wireless e-business termed as $\mathrm{m}$-commerce has the main advantage of portability with ubiquitous business transactions that can be performed anywhere and anytime [1]. In addition to the key mobile features of location-based and personalised information services, payments embedded in mobile apps or websites provide value-added facility that aid in the business agility of organisations in this competitive business environment [2][3]. With recent developments in wireless communication technologies using $3 \mathrm{G}$ evolved to $4 \mathrm{G}$ networks, mobile Internet and multimedia streaming have gained popularity and provide increased channels of interaction with customers [4][5]. Hence, organisations expect that m-commerce provides a cost-effective improvement in their operational efficiency, resulting in an increase in profitability. Businesses have started to consider mobile payments as value-added services providing opportunities for their marketing, promotion and branding [6][7].

Apart from business perspectives, looking at consumer trend in the last decade, most consumers have been using mobile phones beyond the traditional services of voice calls and SMS. By the end of 2016, two thirds of the world's population acquired a mobile subscription with a surge in mobile broadband adoption via smart phones [8]. Mobile devices now account for $60 \%$ of the connections with new services and dedicated apps leveraging on mobile internet that could make common man's daily activities quite convenient. Hence, consumers' expectations from these smart devices have risen dramatically and mobile payment services are now being recognised to be important. Many consumers from countries such as, Finland, UK, North America, Japan, Korea and Singapore started to adopt mobile payments more than a decade back [9][10] as their preferred mode of cashless transactions in their everyday lives - while transacting with vending

Natarajan Meghanathan et al. (Eds) : CCSEA, NCOM, AIFU, DKMP, EMSA, SIPRO, SEA - 2018 
machines, online ticketing agencies, public transport systems and merchant stores. A recent survey in UK indicates that $56 \%$ of smart phone owners purchased a product using a mobile app transaction in 2015 and mobile banking transactions via apps have now been envisaged by consumers [11]. However, global reports indicate that mobile revenue growth is slow [8][12]. There is lack of research in analysing this situation from current technological and business perspectives and such investigations could have a positive influence on mobile payment adoption [7][13]. This provides the key motivation for the study reported here.

This paper is aimed at providing an analysis of the trends in mobile payments, from technology, business, as well as consumer perspectives for analysing the influencing factors. The remainder of the paper is organised as follows. Section 2 describes the need for the study. The influencing factors from various facets of mobile payments are identified and analysed in section 3. Finally, concluding remarks are provided in section 4.

\section{THE NEED FOR THE STUDY}

Despite potential advantages of m-commerce], mobile payments face major challenges as financial transactions via mobile devices demands a multi-faceted approach involving technology innovations, apps and service offerings as well as global business trends [14][15]. In addition, with the emergence of player-centric mobile payment services, new mobile payment business models are being introduced [16]. Both remote and proximity type of mobile payment systems have witnessed evolution of technologies such as Infrared (IR) and Bluetooth combined with services such as Interactive Voice Response (IVR), Short Message Service (SMS), Radio Frequency Identification (RFID)/2D bar codes, Wireless application Protocol (WAP), contactless interface to chip-enabled payment technology, Near-Field Communication (NFC) enabled mobile phones, contactless stickers, tags, mobile browsers, mobile apps and m-wallets [5][17].

With the existing plethora of wireless technologies, both merchants and consumers are clouded with a range of options available to them for adopting mobile payments and are not sure if they are taking the road to success or failure [4][7]. In the past decade, mobile payments were used for predominantly non-banking transactions with several failed initiatives such as Dencoin and Google Wallet even in developed countries [18][19].

On one hand, the banking sector is gradually embracing digital payments capitalising on the IT players such as Apple and Google to compete in the market that may shape its future [12]. On the other hand, the success or failure of mobile payments is based on the consumer acceptance [13]. Recent studies conducted worldwide indicate that mobile payment growth has been slower than anticipated [8][12]. This is because, mobile payments are not just a new technology added on to existing consumer networks, but actually have their own set of historical and normative roots in development practices with an emphasis to be given on market subjects and consumer subjects [7]. Previous studies have predominantly focussed on the technology and payment options available to a consumer based on factors such as location (remote/proximity), payment value (micro/macro amount), and charging method (post-paid/pre-paid), and the associated security protocols [20][21][22]. There is lack of literature that analyses the current multi-faceted dimensions of mobile payments [23][24][25]. There is little guidance available for merchants and consumers to review the various mobile payment options and to adopt those mobile payment methods that suit their requirements.

Due to the paucity of research in this area, this paper analyses various influencing factors for adopting mobile payments. This would help businesses and consumers to make a more systematic review before they embark on the right kind of mobile payments that would add value to their everyday activities. This paper takes a modest step in this direction. 


\section{INFLUENCING FACTORS FOR MOBILE PAYMENTS}

Although some industries such as, retail, entertainment and banking have been successfully adopting mobile options for billing and payment in certain countries, many industries are still cautious in offering mobile payment methods for their customers. This is partly because there are several issues related to mobile payments in an enterprise. On analysing the influencing factors, these could be broadly classified under three main dimensions:

- mobile payment players,

- $\quad$ payment methods and

- $\quad$ enabling wireless technologies

\section{Mobile Payment Players}

There are many parties or players contributing to the mobile payment value chain. In order to access a payment service, a user or subscriber initially has to come into an agreement with a network provider for accessing telecommunication and the payment services provided by the specific operator. If mobile internet is used, an additional contract between a subscriber and an ISP is required. However, with the introduction of $3 \mathrm{G} / 4 \mathrm{G}$ technologies, mobile internet could be accessed directly through their mobile operator. Recent evolutions have enabled users to adopt new mobile payment and billing models for accessing various networks and services independent of the network provider [5][26]. In Table 1, we have summarised a list of players involved in influencing mobile payments in businesses.

Table 1. Mobile Payment Players and Influencing Factors

\begin{tabular}{|l|l|}
\hline \multicolumn{1}{|c|}{ Mobile Payment Players } & \multicolumn{1}{c|}{ Influencing Factors } \\
\hline $\begin{array}{l}\text { Equipment / device } \\
\text { manufacturers }\end{array}$ & $\begin{array}{l}\text { Device usability, features \& constraints, Wireless } \\
\text { technology, Native software, use of third party H/W and } \\
\text { S/W }\end{array}$ \\
\hline Network service providers & $\begin{array}{l}\text { Telecommunication infrastructure, Billing models and } \\
\text { contracts, Integration with payment service providers, QoS, } \\
\text { Network interoperability and Security }\end{array}$ \\
\hline Financial service providers & $\begin{array}{l}\text { Types of e-cash systems, Credit systems, Security and } \\
\text { Payment settlement }\end{array}$ \\
\hline Payment service providers & Interfacing (S/W, H/W and other players), Security and Cost \\
\hline $\begin{array}{l}\text { Market regulators and } \\
\text { consortiums }\end{array}$ & $\begin{array}{l}\text { Governing laws (bank, government and other agencies), } \\
\text { Rights protection, Price regulations and Tax policies }\end{array}$ \\
\hline
\end{tabular}

The abovementioned players need not be exactly mapped onto various business parties but could be an aggregation of business entities. For instance, the network service provider could be aggregating the services of mobile network operators, content providers and Internet service providers. Alternatively, there are cases where the network operator covers the functionality of an Internet service provider, while the content provider caters to payment services as well. Proprietary mobile payment solutions are now being introduced as issuer wallets to compete with device manufacturers such as Apple, Samsung, etc. Hence, an evolution of such industry players have a major influence on the consumer adoption of mobile payments.

\section{Payment Methods}

Though mobile payment services were traditionally managed by mobile network operators for many years using player-centric models, recently we find the emergence of new payment and billing models that allow consumers to access the payment services independent of who the 
owner of the service is [13][27]. The issue of mobile payment adoption is further compounded by the types of payment methods supported here. Commonly used payment methods include prepaid cash card, micro-billing, person-to-person (P2P) and credit card payments. Some of the main factors that influence these payment methods in m-commerce are identified in Table 2.

Table 2. Payment Methods and Influencing Factors

\begin{tabular}{|l|l|}
\hline \multicolumn{1}{|c|}{ Payment Methods } & \multicolumn{1}{c|}{ Influencing Factors } \\
\hline Pre-paid cash card & $\begin{array}{l}\text { Small transaction amount, Top-up methods and Availability } \\
\text { to anyone }\end{array}$ \\
\hline Micro-billing & Billing options, Service charge and Transaction maintenance \\
\hline Person-to-person (P2P) & $\begin{array}{l}\text { Direct credit or debit options, Service charge, Account } \\
\text { maintenance and Security }\end{array}$ \\
\hline Credit card & $\begin{array}{l}\text { Service provider trust, M-wallets (H/W and S/W integration) } \\
\text { and Security }\end{array}$ \\
\hline
\end{tabular}

Similar to Internet-based online payment methods that support pre-paid (debit) and post-paid (credit) services, mobile payments require an integrated flexible model that support quality of service (QoS) with one-stop billing schemes for the end-users [21].

\section{Enabling Wireless Technologies}

The aforesaid payment methods could be adopted to make mobile payment transactions using different wireless technologies. Such mobile payments go through a set of wireless security levels which is a key factor in providing consumer trust and confidence [28]. The enabling wireless technologies could support mobile security elements that are either removable or nonremovable from the mobile device [24]. Removable security elements could be a single chip, a dual chip or a dual slot, while non-removable security elements could support embedded hardware and software modules, including personalised biometric technologies [13]. In table 3, we identify a list of wireless technologies commonly adopted in businesses and their influencing factors for mobile payment adoption.

Table 3. Enabling Wireless Technologies and Influencing Factors

\begin{tabular}{|l|l|}
\hline Enabling Wireless Technologies & \multicolumn{1}{c|}{ Influencing Factors } \\
\hline $\begin{array}{l}\text { Radio Frequency Identification } \\
\text { (RFID) }\end{array}$ & $\begin{array}{l}\text { Transponder \& reader frequencies / range, Encryption } \\
\text { methods and Payment methods }\end{array}$ \\
\hline Short Message Service (SMS) & $\begin{array}{l}\text { SMS gateway QoS, Payment methods, Merchant port ID } \\
\text { and Push technology }\end{array}$ \\
\hline $\begin{array}{l}\text { Wireless Access Protocol } \\
\text { (WAP) using WIM chip }\end{array}$ & $\begin{array}{l}\text { Dual chip phones, WIM certificate, Payment methods, } \\
\text { Security and Account Maintenance }\end{array}$ \\
\hline Infrared (IR) & Point-to-point range, Fault-tolerance and Payment methods \\
\hline Bluetooth & Security, Transmission time and Data volume \\
\hline $\begin{array}{l}\text { Near Field Communication } \\
\text { (NFC) }\end{array}$ & $\begin{array}{l}\text { Tokenisation, Mobile phones, NFC reader, Payment } \\
\text { methods }\end{array}$ \\
\hline Internet & $\begin{array}{l}\text { Mobile Apps for Payments, M-wallets, Security, Payment } \\
\text { Methods, Account Maintenance \& Fees }\end{array}$ \\
\hline
\end{tabular}

A mobile payment system typically espouses several wireless technologies with different possible payment methods and with different player-centric influencing factors. With security being a major concern in mobile payments, security modules with digital signatures are being implemented in the form of WAP Identity Module (WIM) cards. From traditional, simple Interactive Voice Response (IVR) systems adopted in phone banking to enhanced WIM chips in mobile devices and now with sophisticated mobile apps, the use of different wireless technologies 
involves different levels of security as the device moves in and out of multiple wireless networks leading to many security issues [17].

\section{CONCLUSIONS}

The adoption of mobile payment is constricted by multi-faceted issues that can be approached from several angles. This paper identified three main dimensions such as mobile payment players, payment methods and enabled wireless technologies. An analysis resulted in their influencing factors for a successful mobile payment adoption. These influencing factors would facilitate consumers, businesses and researchers to consider the different mobile payment solutions, from technology as well as business perspectives for decision making.

\section{REFERENCES}

[1] Koss, V., Miles, J. and Boyes, E. (2013). "M-commerce Comes of Age: Collaborate to Succeed," Journal of Payments Strategy \& Systems, vol. 7, no. 1., pp. 50-60

[2] Buhan, D., Cheong, Y.C. and Tan, C.L. (2002) 'Mobile payments in m-commerce', Wireless Internet Centre Report, Gemini Ernst \& Young.

[3] Wyse, J.E. (2003) 'Supporting m-commerce transactions incorporating locational attributes: an evaluation of the comparative performance of a location-aware method of locations repository management', International Journal of Mobile Communications, Vol. 1, Nos. 1-2, pp.119-147.

[4] Mathew M, Balakrishnan N, Pratheeba S (2010) A study on the success potential of multiple mobile payment technologies. In: Technology management for global economic growth (PICMET), Proceedings of PICMET ' 10

[5] Pukkasenung P. and Chokngamwong R. 2016 Review and Comparison of Mobile Payment Protocol, J.J.(Jong Hyuk) Park et al. (eds.), Advances in Parallel and Distributed Computing and Ubiquitous Services, Lecture Notes in Electrical Engineering, Springer, pp 11-20.

[6] Lee, C.P., Warkentin, M. and Choi, H. (2004), The Role of Technological and Social Factors on the Adoption of Mobile Payment Technologies, proceedings of the 10th Americas Conference on Information Systems (AMCIS), New York, August, pp. 2781-2786.

[7] Kremers, R. and Brassett J. (2017) Mobile Payments, Social Money: Everyday Politics of the Consumer Subject, New Political Economy, DOI: 0.1080/13563467.2017.1306503.

[8] GSMA White Paper (2017), The Mobile Economy, GSMA.

[9] Anil, S., Ting, L.T., Moe, L.H. and Jonathan, G.P. (2003) 'Overcoming barriers to the successful adoption of mobile commerce in Singapore', International Journal of Mobile Communications, Vol. 1, Nos. 1-2, pp.194-231.

[10]Elliott, G. and Tang, H. (2004) 'The wireless mobile internet: an international and historical comparison of the European and American wireless application protocol (WAP) and the Japanese iMode service', International Journal of Information Technology and Management, Vol. 3, No. 2/3/4.

[11] EMV White Paper, (2017), Payment Tokenisation Specification EMVCo.

[12] EY White paper (2017), Mobile money — the next wave of growth, Ernst and Young.

[13] BCG White Paper (2017), Digital Payments 2020, BCG Boston Consulting Group. 
[14] Ondrus, J. and Pigneur, Y. (2006),Towards a holistic analysis of mobile payments: a multiple perspectives approach, Electronic Commerce Research and Applications, 5(3), pp. 246-257. Ondrus, J. and Pigneur, Y. (2007), An assessment of NFC for future mobile payment systems, proceedings of the International Conference on Mobile Business (ICMB'07),Toronto, July, pp. 43-53.

[15] Mobile Wallet Report (2017) Study of Mobile Banking \& Payments First Annapolis Consulting, Inc. I

[16] Yuan, Y. and Zhang, J.J. (2003) 'Towards an appropriate business model for m-commerce', International Journal of Mobile Communications, Vol. 1, Nos. 1-2, pp.35-56.

[17] Hayashi, F. (2012). "Mobile Payments: What's in It for Consumers?" Fed-eral Reserve Bank of Kansas City, Economic Review, vol. 97, no. 1, pp. 35-66.

[18] Mallat, N. (2007), Exploring consumer adoption of mobile payments - A qualitative study, The Journal of Strategic Information Systems, 16(4), pp. 413-432.

[19] Carton, F, Hedman, J, Dennehy, D, Damsgaard, J, Tan, K and McCarthy, J, B. (2012), "Framework for Mobile Payments Integration" The Electronic Journal Information Systems Evaluation Vol. 15 No.1, pp.14-25.

[20] Ghosh, A. and Swaminatha, T. (2001) 'Software security and privacy risks in mobile e-commerce', Communications of the ACM, Vol. 44, No. 2, pp.51-57.

[21] Koutsopoulou, M. et al. (2004) 'An integrated charging, accounting and billing management platform for the support of innovative business models in mobile networks', International Journal of Mobile Communications, Vol. 2, No. 4, pp. 418-434.

[22]Fun TS, Beng LY, Razali MN (2013) Review of mobile macro-payments schemes. Journal of Advances in Computer Networks, Vol. 1, No. 4, pp. 323-328

[23] Singh A, Shahazad KS (2012) A review: secure payment system for electronic transaction. International Journal of Advanced Research in Computer Science and Software Engineering, Vol. 2, No. 3, pp. 236-243

[24] Ahamad SS, Udgata SK, Nair M (2014) A secure lightweight and scalable mobile payment framework. In: FICTA 2013. Advances in intelligent system and computing, vol 247. Springer International Publishing, Switzerland, pp. 545-553.

[25] Venkatraman, S. (2008), 'Mobile Payment Implementation - A Reference Framework', International Journal of Business Information Systems, 3, 3, pp. 252-271.

[26] Xu, W. (2017), The Study of WeChat Payment Users Willingness Factor, Journal of Service Science and Management, 10, 251-259

[27] Au, Y.A. and Kauffman, R.J. (2008), The economics of mobile payments: Understanding stakeholder issues for an emerging financial technology application, Electronic Commerce Research and Applications, (7), pp. 141-164.

[28] PwC Mobile Payment Report 2017, Price Waterhouse Coopers. 


\section{AUTHORS}

Dr. Sita Venkatraman earned her $\mathrm{PhD}$ in Computer Science, with a doctoral thesis titled "Efficient Parallel Algorithms for Pattern Recognition", from National Institute of Industrial Engineering in 1993. In the past 30 years, Sita's work experience involves both industry and academics - developing turnkey projects for IT industry and teaching a variety of IT courses for tertiary institutions, in India, Singapore, New Zealand, and more recently in Australia since 2007. She currently works as Lecturer (Information Technology) at the School of Engineering, Construction \& Design, Melbourne Polytechnic, Australia. She also serves as Member of Register of Experts at Australia's Tertiary Education Quality and Standards Agency (TEQSA).

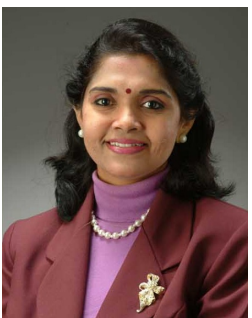

Dr. Venkatraman's. recent research areas are predominantly in Business Intelligence, Data Mining, Cloud Computing, Information Security and Health Informatics. She has published eight book chapters and more than 120 research papers in internationally well-known refereed journals and conferences.. 